\title{
CRÓNICA PARLAMENTARIA DEL CONGRESO DE LOS DIPUTADOS (I)
}

\author{
AURORA GUTIÉRREZ NOGUEROLES \\ Profesora Asociada de Derecho Constitucional \\ UNED
}




\section{SUMARIO}

I. Actividad legislativa.-1. Leyes.-1.1. Leyes orgánicas.1.2. Leyes ordinarias.-2. Tratados y convenios internacionales.-3. Decretos-leyes.-4. Decretos legislativos.-5. Proposiciones de ley.-II. Actividad no LeGISLATIVA.-1. Interpelaciones.-1.1. Interpelaciones de tramitación urgente.1.2. Interpelaciones de tramitación ordinaria.-2. Preguntas.-3. Mociones consecuencia de interpelación.-4. Proposiciones no de ley.-5. Comparecencias informativas.5.1. Comparecencias ante el Pleno.-5.2. Comparecencias en Comisión.-6. Debates generales. 


\title{
CRÓNICA PARLAMENTARIA DEL CONGRESO DE LOS DIPUTADOS (I) $(*)$
}

\author{
POR \\ AURORA GUTIÉRREZ NOGUEROLES \\ Profesora Asociada de Derecho Constitucional \\ UNED
}

La presente crónica se plantea como objetivo resumir la actividad parlamentaria desarrollada desde el inicio del primer período de sesiones, que comienza en septiembre de 1991, hasta el 12 de abril de 1993, fecha en que finaliza la IV Legislatura. La extensión de tal espacio temporal y la intensidad de la actividad desarrollada en él obligan a resumir algunos de los apartados en que hemos considerado conveniente desglosar este trabajo.

Así pues, con esta crónica-resumen se pretende hacer una selección referida tanto a la actividad legislativa como a la no legislativa, llevada a cabo por el Congreso durante el período de tiempo mencionado.

\section{ACTIVIDAD LEGISLATIVA}

1. LEYES

\subsection{Leyes orgánicas}

Durante el período antes delimitado se han aprobado un total de once leyes orgánicas, que se relacionan a continuación:

(*) Primera parte. 


\begin{tabular}{|c|c|c|c|}
\hline "B.O.C.G." & Materia & N.는 & Fecha «B.O.E." \\
\hline $\mathrm{A} 060$ & Servicio militar & 013 & $21 / 12 / 91$ \\
\hline A057 & Protección de la seguridad ciudadana & 001 & $22 / 02 / 92$ \\
\hline B063 & $\begin{array}{l}\text { Modificación de la Ley Orgánica } 3 / 1981 \text {, de } 6 \text { de abril } \\
\text { del Defensor del Pueblo, a efectos de constituir una } \\
\text { Comisión Mixta Congreso-Senado de Relaciones con } \\
\text { el Defensor del Pueblo }\end{array}$ & 002 & $06 / 03 / 92$ \\
\hline A072 & $\begin{array}{l}\text { Supuestos de contrabando en materia de exportación } \\
\text { de material de defensa o material de doble uso }\end{array}$ & 003 & $01 / 05 / 92$ \\
\hline A061 & $\begin{array}{l}\text { Reforma de la Ley reguladora de la competencia y el } \\
\text { procedimiento de los Juzgados de Menores }\end{array}$ & 004 & $11 / 06 / 92$ \\
\hline A059 & $\begin{array}{l}\text { Regulación del tratamiento automatizado de los datos } \\
\text { de carácter personal }\end{array}$ & 005 & $31 / 10 / 92$ \\
\hline $\mathrm{B} 107$ & $\begin{array}{l}\text { Modificación de los artículos } 72,73 \text { y } 141 \text { de la Ley } \\
\text { Orgánica } 5 / 1985 \text {, de } 19 \text { de junio, del Régimen Electoral } \\
\text { General }\end{array}$ & 006 & $03 / 11 / 92$ \\
\hline A093 & $\begin{array}{l}\text { Fijación de la edad de jubilación de jueces y } \\
\text { magistrados e integración de diverso personal médico } \\
\text { en el Cuerpo de Médicos Forenses }\end{array}$ & 007 & $21 / 11 / 92$ \\
\hline A101 & $\begin{array}{l}\text { Modificación del Código Penal y de la Ley de } \\
\text { Enjuiciamiento Criminal en materia de tráfico } \\
\text { de drogas }\end{array}$ & 008 & $24 / 12 / 92$ \\
\hline A096 & $\begin{array}{l}\text { Transferencia de competencias a Comunidades } \\
\text { Autónomas que accedieron a la autonomía por la vía } \\
\text { del artículo } 149 \text { de la Constitución }\end{array}$ & 009 & $24 / 12 / 92$ \\
\hline A098 & $\begin{array}{l}\text { Autorización para la ratificación por España del } \\
\text { Tratado de la Unión Europea, firmado en Maastricht } \\
\text { el } 7 \text { de febrero de } 1992\end{array}$ & 010 & $29 / 12 / 92$ \\
\hline
\end{tabular}

\subsection{Leyes ordinarias}

Se han aprobado un total de cincuenta y nueve leyes, de las que se destacan las siguientes: 


\begin{tabular}{|c|c|c|c|}
\hline "B.O.C.G." & Materia & N. Ley & Fecha «B.O.E.» \\
\hline $\mathrm{A} 052$ & $\begin{array}{l}\text { Modificación de la Ley por la que se establecen las } \\
\text { bases del régimen jurídico de las Cámaras Agrarias }\end{array}$ & 23 & $17 / 10 / 91$ \\
\hline A058 & $\begin{array}{l}\text { Autorización para la participación de España como } \\
\text { miembro fundador del Banco Europeo de } \\
\text { Reconstrucción y Desarrollo }\end{array}$ & 24 & $26 / 11 / 91$ \\
\hline A056 & $\begin{array}{l}\text { Establecimiento de una nueva organización de las } \\
\text { entidades de crédito de capital público estatal } \\
\text { (procedente del Real Decreto-Ley } 3 / 91 \text {, de } 3 \text { de mayo) }\end{array}$ & 25 & $26 / 11 / 91$ \\
\hline A053 & $\begin{array}{l}\text { Contratos celebrados fuera de establecimientos } \\
\text { mercantiles }\end{array}$ & 26 & $26 / 11 / 91$ \\
\hline B068 & $\begin{array}{l}\text { Regulación del reconocimiento de determinados } \\
\text { empleos militares }\end{array}$ & 27 & $06 / 12 / 91$ \\
\hline B049 & $\begin{array}{l}\text { Derogación de la Ley } 197 / 1963 \text {, de } 28 \text { de diciembre, } \\
\text { sobre centros y zonas de interés turístico nacional }\end{array}$ & 28 & $06 / 12 / 91$ \\
\hline A068 & $\begin{array}{l}\text { Adecuación de determinados conceptos impositivos } \\
\text { a las Directivas y Reglamentos de las Comunidades } \\
\text { Europeas }\end{array}$ & 29 & $17 / 12 / 91$ \\
\hline A055 & $\begin{array}{l}\text { Modificación del Código Civil en materia de } \\
\text { testamentos }\end{array}$ & 30 & $23 / 12 / 91$ \\
\hline A063 & Presupuestos Generales del Estado para 1992 & 31 & $31 / 12 / 91$ \\
\hline A069 & Arrendamientos rústicos históricos & 01 & $11 / 02 / 92$ \\
\hline B065 & $\begin{array}{l}\text { Denominación oficial como Girona y Lleida de las } \\
\text { provincias de Gerona y Lérida }\end{array}$ & 02 & $29 / 02 / 92$ \\
\hline B070 & $\begin{array}{l}\text { Medidas de corrección de la Ley } 38 / 1988 \text {, de } 28 \\
\text { de diciembre, de Demarcación y Planta Judicial }\end{array}$ & 03 & $21 / 03 / 92$ \\
\hline B074 & $\begin{array}{l}\text { Por la que se declara reserva natural a las marismas } \\
\text { de Santoña y Noja }\end{array}$ & 06 & $30 / 03 / 92$ \\
\hline B096 & $\begin{array}{l}\text { Modificación del régimen de permisos concedidos } \\
\text { por Leyes } 8 / 1980 \text {, del Estatuto de Trabajadores, } \\
\text { y 30/1984, de Medidas para la Reforma de la Función } \\
\text { Pública, a los adoptantes de un menor de cinco años }\end{array}$ & 08 & $01 / 05 / 92$ \\
\hline A062 & Mediación en seguros privados & 09 & $02 / 05 / 92$ \\
\hline$A 080$ & Medidas urgentes de reforma procesal & 10 & $05 / 05 / 92$ \\
\hline $\mathrm{A} 070$ & $\begin{array}{l}\text { Autorización a la participación de España en la sexta } \\
\text { reposición de recursos del Fondo Africano de Desarrollo }\end{array}$ & 11 & $26 / 05 / 92$ \\
\hline
\end{tabular}




\begin{tabular}{|c|c|c|c|}
\hline "B.O.C.G." & Materia & N. ${ }^{2}$ Ley & Fecha "B.O.E." \\
\hline A067 & Contrato de agencia & 12 & $29 / 05 / 92$ \\
\hline A071 & $\begin{array}{l}\text { Recursos propios y supervisión en base consolidada } \\
\text { de las entidades financieras }\end{array}$ & 13 & $02 / 06 / 92$ \\
\hline A077 & $\begin{array}{l}\text { Comienzo de la aplicación del Impuesto General } \\
\text { Indirecto Canario el } 1 \text { de enero de } 1993 \text { y modificación } \\
\text { parcial de las tarifas del Arbitrio sobre la producción } \\
\text { e importación en las islas Canarias (procedente del } \\
\text { Real Decreto-Ley } 5 / 1991 \text {, de } 20 \text { de diciembre) }\end{array}$ & 14 & $11 / 06 / 92$ \\
\hline $\mathrm{A} 075$ & $\begin{array}{l}\text { Medidas urgentes para la progresiva adaptación del } \\
\text { sector petrolero al marco comunitario (procedente } \\
\text { del Real Decreto-Ley } 4 / 1991 \text {, de } 29 \text { de noviembre) }\end{array}$ & 15 & $11 / 06 / 92$ \\
\hline A084 & $\begin{array}{l}\text { Concurrencia de España al noveno aumento de cuotas } \\
\text { del Fondo Monetario Internacional }\end{array}$ & 16 & $19 / 06 / 92$ \\
\hline A083 & Creación de la Universidad de La Rioja & 17 & $19 / 06 / 92$ \\
\hline A086 & $\begin{array}{l}\text { Por la que se establecen determinadas normas en } \\
\text { materia de inversiones extranjeras en España }\end{array}$ & 18 & $03 / 07 / 92$ \\
\hline A074 & $\begin{array}{l}\text { Sobre régimen de sociedades y fondos de titulación } \\
\text { hipotecaria }\end{array}$ & 19 & $14 / 07 / 92$ \\
\hline A076 & $\begin{array}{l}\text { Modificación de la Ley } 22 / 1987 \text {, de } 11 \text { de noviembre, } \\
\text { de Propiedad Intelectual }\end{array}$ & 20 & $14 / 07 / 92$ \\
\hline A081 & Industria & 21 & $23 / 07 / 92$ \\
\hline A085 & $\begin{array}{l}\text { Medidas urgentes sobre fomento del empleo y } \\
\text { protección por desempleo (procedente del Real } \\
\text { Decreto-Ley } 1 / 1992 \text {, de } 3 \text { de abril) }\end{array}$ & 22 & $04 / 08 / 92$ \\
\hline A066 & Seguridad privada & 23 & $04 / 08 / 92$ \\
\hline B147 & $\begin{array}{l}\text { Reforma del artículo 13, apartado 2, de la Constitución } \\
\text { Española }\end{array}$ & $\mathrm{C}$ & $28 / 08 / 92$ \\
\hline A090 & $\begin{array}{l}\text { Acuerdo de cooperación del Estado con la Federación } \\
\text { de Entidades Religiosas Evangélicas de España }\end{array}$ & 24 & $12 / 11 / 92$ \\
\hline $\mathrm{A} 091$ & $\begin{array}{l}\text { Acuerdo de cooperación del Estado con la Federación } \\
\text { de Comunidades Israelitas de España }\end{array}$ & 25 & $12 / 11 / 92$ \\
\hline A092 & $\begin{array}{l}\text { Acuerdo de cooperación del Estado con la Comisión } \\
\text { Islámica de España }\end{array}$ & 26 & $12 / 11 / 92$ \\
\hline $\mathrm{A} 078$ & Puertos del Estado y de la Marina Mercante & 27 & $25 / 11 / 92$ \\
\hline
\end{tabular}




\begin{tabular}{|c|c|c|c|}
\hline «B.O.C.G.» & Materia & N..ㄴoy & Fecha "B.O.E." \\
\hline \multirow[t]{2}{*}{ A097 } & $\begin{array}{l}\text { Medidas presupuestarias urgentes (procedente } \\
\text { del Real Decreto-Ley } 5 / 1992 \text {, de } 21 \text { de julio) }\end{array}$ & 28 & $25 / 11 / 92$ \\
\hline & $\begin{array}{l}\text { Propuesta de reforma del artículo } 49.4 \text { del Reglamento } \\
\text { del Senado }\end{array}$ & G & $25 / 11 / 92$ \\
\hline A082 & $\begin{array}{l}\text { Régimen jurídico de las Administraciones Públicas } \\
y \text { del Procedimiento Administrativo Común }\end{array}$ & 30 & $27 / 11 / 92$ \\
\hline A100 & $\begin{array}{l}\text { Incentivos fiscales aplicables a la realización del Proyecto } \\
\text { Cartuja } 93\end{array}$ & 31 & $27 / 11 / 92$ \\
\hline A079 & $\begin{array}{l}\text { Modificación de la Ley } 31 / 1987 \text {, de } 18 \text { de diciembre, } \\
\text { de Ordenación de las Telecomunicaciones. }\end{array}$ & 32 & $04 / 12 / 92$ \\
\hline B142 & $\begin{array}{l}\text { Modificación de Ley } 12 / 1986 \text { sobre regulación de las } \\
\text { atribuciones profesionales de arquitectos e ingenieros } \\
\text { técnicos }\end{array}$ & 33 & $10 / 12 / 92$ \\
\hline A094 & Ordenación del sector petrolero & 34 & $24 / 12 / 92$ \\
\hline A106 & Regulación de la televisión por satélite & 35 & $24 / 12 / 92$ \\
\hline B115 & $\begin{array}{l}\text { Modificación del Estatuto de los Trabajadores en } \\
\text { materia de indemnización en los supuestos de } \\
\text { extinción contractual por jubilación del empresario }\end{array}$ & 36 & $29 / 12 / 92$ \\
\hline A108 & Impuesto sobre el Valor Añadido & 37 & $29 / 12 / 92$ \\
\hline A110 & Impuestos Especiales & 38 & $29 / 12 / 92$ \\
\hline A104 & Presupuestos Generales del Estado para 1993 & 39 & $30 / 12 / 92$ \\
\hline A095 & $\begin{array}{l}\text { Por la que se autoriza la participación de España en } \\
\text { la quinta reposición de recursos del Fondo Asiático } \\
\text { de Desarrollo }\end{array}$ & 01 & $09 / 03 / 93$ \\
\hline A107 & $\begin{array}{l}\text { Derogación de los artículos } 75 \text { y } 76 \text { de la Ley } 25 / 1970, \\
\text { de } 2 \text { de diciembre, Estatuto de la Viña, del Vino y de } \\
\text { los Alcoholes }\end{array}$ & 02 & $18 / 03 / 93$ \\
\hline A103 & $\begin{array}{l}\text { Básica de las Cámaras Oficiales de Comercio, } \\
\text { Industria y Navegación }\end{array}$ & 03 & $23 / 03 / 93$ \\
\hline B116 & $\begin{array}{l}\text { Modificación de la Ley } 26 / 1990 \text {, de } 20 \text { de diciembre, } \\
\text { sobre actualización periódica del límite máximo de } \\
\text { ingresos anuales para acceder a la asignación } \\
\text { económica por hijo a cargo }\end{array}$ & 04 & $31 / 03 / 93$ \\
\hline
\end{tabular}




\begin{tabular}{llll}
\hline "B.O.C.G." & \multicolumn{1}{c}{ Materia } & N. ${ }^{2}$ Ley & Fecha "B.O.E." \\
\hline A105 & $\begin{array}{l}\text { Liquidación definitiva de la participación de las } \\
\text { Corporaciones Locales en los tributos del Estado, } \\
\text { correspondiente al ejercicio de 1990 }\end{array}$ & 05 & 17/04/93 \\
\hline A127 & $\begin{array}{l}\text { Aprobación de la metodología de determinación del } \\
\text { cupo del País Vasco para el quinquenio 1992-1996 }\end{array}$ & 07 & $17 / 04 / 93$ \\
\hline A115 & $\begin{array}{l}\text { Reconocimiento de la Universidad "San Pablo-CEU" } \\
\text { de Madrid }\end{array}$ & 08 & $20 / 04 / 93$ \\
\hline A111 & $\begin{array}{l}\text { Reconocimiento de la Universidad "Alfonso X el Sabion" } \\
\text { de Madrid }\end{array}$ & 09 & $20 / 04 / 93$ \\
\hline A116 & $\begin{array}{l}\text { Modificación del régimen de puestos de trabajo } \\
\text { reservados a funcionarios de Administración Local } \\
\text { con habilitación de carácter nacional }\end{array}$ & 10 & $22 / 04 / 93$ \\
\hline
\end{tabular}

\section{TRATADOS Y CONVENIOS INTERNACIONALES}

Haciendo abstracción de los Tratados que requieren, de modo excepcional, una ley orgánica que autorice su celebración (art. $93 \mathrm{CE}$ ), la actividad parlamentaria más frecuente en relación con los distintos tipos de acuerdos internacionales se desarrolla conforme a lo previsto en los apartados 1 y 2 del artículo $94 \mathrm{CE}$. De esta forma, cabe distinguir entre los tratados o convenios de cuya celebración las Cortes son meramente informadas $y$ aquellos otros que exigen para su validez la previa autorización de las Cámaras legislativas. Respecto de los primeros (esto es, los del art. 94.2), es de señalar que, durante el período analizado, han sido remitidos al Congreso para su conocimiento un total de cuarenta y cuatro convenios internacionales. En cuanto a los aludidos en segundo lugar, se han aprobado, de conformidad con lo dispuesto en el citado artículo 94.1 $C E$, ciento veinticuatro acuerdos internacionales, de los que enumeramos selectivamente los siguientes: 


\begin{tabular}{|c|c|c|c|}
\hline "B.O.C.G." & Materia & Fecha debate & N.. Expte. \\
\hline C157 & $\begin{array}{l}\text { Convenio "Andrés Bello" de integración educativa, } \\
\text { tecnológica y cultural, hecho en Madrid el } 27 / 11 / 90\end{array}$ & $10 / 10 / 91$ & $110 / 121$ \\
\hline C159 & $\begin{array}{l}\text { Acuerdo interno relativo a las medidas y a los } \\
\text { procedimientos para la aplicación del cuarto } \\
\text { Convenio ACP-CEE, hecho en Bruselas el 16/07/90 }\end{array}$ & $10 / 10 / 91$ & $110 / 122$ \\
\hline $\mathrm{C} 160$ & $\begin{array}{l}\text { Acuerdo interno relativo a la financiación y gestión } \\
\text { de las ayudas de la Comunidad dentro del cuarto } \\
\text { Convenio ACP-CEE, hecho en Bruselas el 16/07/90 }\end{array}$ & $10 / 10 / 91$ & $110 / 123$ \\
\hline C162 & $\begin{array}{l}\text { Acuerdo entre los Estados miembros de la CEE } \\
\text { relativo a la simplificación y a la modernización de } \\
\text { las formas de transmisión de las solicitudes de } \\
\text { extradición, hecho en San Sebastián el } 26 / 05 / 89\end{array}$ & $10 / 10 / 91$ & $110 / 125$ \\
\hline$C 168$ & $\begin{array}{l}\text { Convenio constitutivo del Grupo Internacional de } \\
\text { Estudios sobre el Caucho, fundado en } 1944\end{array}$ & $10 / 10 / 91$ & $110 / 129$ \\
\hline C170 & $\begin{array}{l}\text { Convenio Internacional del Yute y de los Productos } \\
\text { del Yute, hecho en Ginebra el } 03 / 11 / 89\end{array}$ & $10 / 10 / 91$ & $110 / 131$ \\
\hline C174 & $\begin{array}{l}\text { Convenio de administración de programa entre la } \\
\text { Comisión de la CEE y España para el Proyecto } \\
\text { Ala/89/9: "Programa de Apoyo a la Pequeña y } \\
\text { Mediana Industria en Centroamérica». Fase ll y } \\
\text { Anejos. Firmado "ad referendum" }\end{array}$ & $10 / 10 / 91$ & $110 / 134$ \\
\hline C181. & $\begin{array}{l}\text { Constitución y Convenio de la Unión Internacional } \\
\text { de Telecomunicaciones (UIT), hechos en Niza el } \\
\text { 30/06/89, y declaraciones a formular por España }\end{array}$ & $12 / 12 / 91$ & $110 / 137$ \\
\hline C182 & $\begin{array}{l}\text { Canje Cartas de } 17 \text { y 25/05/91, constitutivo de } \\
\text { Acuerdo-programa de NN.UU. para el medio } \\
\text { ambiente y España, relativo al tercer periodo de } \\
\text { sesiones grupo de trabajo expertos jurídicos y } \\
\text { técnicos de diversidad biológica }\end{array}$ & $12 / 12 / 91$ & $110 / 138$ \\
\hline C184 & $\begin{array}{l}\text { Convenio sobre el reconocimiento y actualización } \\
\text { de los libros de estado civil (Patras, } 7 / 09 / 89 \text { ), } \\
\text { firmado por España el } 5 / 06 / 90, \text { y declaraciones a } \\
\text { formular por España }\end{array}$ & $12 / 12 / 91$ & $110 / 140$ \\
\hline C190 & $\begin{array}{l}\text { Convenio sobre supresión de la doble imposición } \\
\text { en caso de corrección de beneficios empresas } \\
\text { asociadas (Bruselas, 23/07/90), así como } \\
\text { declaraciones comunes y unilaterales, comprendida } \\
\text { la del Estado español }\end{array}$ & $12 / 12 / 91$ & $110 / 143$ \\
\hline
\end{tabular}




\begin{tabular}{|c|c|c|c|}
\hline "B.O.C.G." & Materia & Fecha debate & $N .^{\circ}$ Expte. \\
\hline C194 & $\begin{array}{l}\text { Acuerdo adhesión de España al Convenio de } \\
\text { Schlegen de } 14 / 06 / 85 \text {, entre los Gobiernos de los } \\
\text { Estados de la Unión Económica Benelux, Alemania } \\
\text { y Francia, sobre la supresión gradual de controles en } \\
\text { fronteras comunes, firmado en Schlegen el 19/06/90 }\end{array}$ & $13 / 02 / 92$ & $110 / 146$ \\
\hline C195 & $\begin{array}{l}\text { Convenio n. }{ }^{\circ} 135 \text { del Consejo de Europa, contra el } \\
\text { dopaje, hecho en Estrasburgo el } 16 / 11 / 89\end{array}$ & $13 / 02 / 92$ & $110 / 147$ \\
\hline C197 & $\begin{array}{l}\text { Enmienda al Protocolo de Montreal relativo a las } \\
\text { sustancias que agotan la capa de ozono (Londres, } \\
29 / 06 / 90 \text { ) }\end{array}$ & $13 / 02 / 92$ & $110 / 149$ \\
\hline $\mathrm{C} 205$ & $\begin{array}{l}\text { Tratado sobre fuerzas armadas convencionales en } \\
\text { Europa, hecho en París el } 19 / 11 / 90 \text {, así como } \\
\text { declaración en el Instrumento español de ratificación } \\
\text { del Tratado sobre Gibraltar }\end{array}$ & $13 / 02 / 92$ & $110 / 152$ \\
\hline C208 & $\begin{array}{l}\text { Modificación Convenio Postal Universal y Protocolo } \\
\text { Final (Washington, 14/12/89) }\end{array}$ & $27 / 02 / 92$ & $110 / 155$ \\
\hline$C 210$ & $\begin{array}{l}\text { Adhesión de España al Protocolo para la protección } \\
\text { de bienes culturales en caso de conflicto armado, } \\
\text { anejo a Convención de La Haya de 14/05/1954 }\end{array}$ & $27 / 02 / 92$ & $110 / 157$ \\
\hline $\mathrm{C} 223$ & $\begin{array}{l}\text { Protocolo para instituir Comisión de Conciliación y } \\
\text { Buenos Oficios, facultada para resolver controversias } \\
\text { que pueda dar lugar la Convención relativa a la lucha } \\
\text { contra las discriminaciones en enseñanza (Paris, } \\
18 / 12 / 62 \text { ) }\end{array}$ & $27 / 02 / 92$ & $110 / 168$ \\
\hline $\mathrm{C} 225$ & $\begin{array}{l}\text { Protocolo del Acuerdo para importación de objetos } \\
\text { de carácter educativo, científico o cultural, hecho en } \\
\text { Nairobi el } 26 / 11 / 76 \text {, así como declaración a formular } \\
\text { por España }\end{array}$ & $27 / 02 / 92$ & $110 / 170$ \\
\hline$C 229$ & $\begin{array}{l}\text { Convenio relativo a la cofinanciación del Proyecto } \\
\text { Ala/87/14 y anexo entre España y la CEE, hecho en } \\
\text { Madrid el } 30 / 06 / 89\end{array}$ & $09 / 04 / 92$ & $110 / 172$ \\
\hline C232 & $\begin{array}{l}\text { Acuerdo entre los Gobiernos de Francia, Alemania, } \\
\text { Reino Unido de Gran Bretaña e Irlanda del Norte, } \\
\text { España y Bélgica, concerniente al Programa Airbus } \\
\text { A-320, hecho en Bonn el 6/02/91 }\end{array}$ & $09 / 04 / 92$ & $110 / 175$ \\
\hline $\mathrm{C} 233$ & $\begin{array}{l}\text { Denuncia Convenio } n .989 \text { de la OlT sobre trabajo } \\
\text { nocturno de las mujeres empleadas en la industria } \\
\text { (revisado en 1948), adoptado en Ginebra el } \\
9 / 07 / 1948\end{array}$ & $18 / 02 / 92$ & $110 / 179$ \\
\hline
\end{tabular}




\begin{tabular}{|c|c|c|c|}
\hline "B.O.C.G.» & Materia & Fecha debate & N.. Expte. \\
\hline C310 & $\begin{array}{l}\text { Convenio } n .9172 \text { de la OIT sobre las condiciones } \\
\text { de trabajo en los hoteles, restaurantes y } \\
\text { establecimientos similares, adoptado en Ginebra } \\
\text { el } 25 / 06 / 91\end{array}$ & $25 / 02 / 93$ & $110 / 239$ \\
\hline C311 & $\begin{array}{l}\text { Convenio de adhesión de España al Convenio de } \\
\text { la CEE sobre ley aplicable a las obligaciones } \\
\text { contractuales, abierto a la firma en Roma el 19/06/80, } \\
\text { hecho en Funchal el 18/05/92, y declaración a } \\
\text { formular por España }\end{array}$ & $25 / 02 / 93$ & $110 / 240$ \\
\hline C315 & $\begin{array}{l}\text { Acuerdos europeos de asociación entre la CEE y } \\
\text { Polonia, firmados el } 16 / 12 / 91\end{array}$ & $25 / 02 / 93$ & $110 / 242$ \\
\hline C316 & $\begin{array}{l}\text { Acuerdos europeos de asociación entre la CEE y } \\
\text { Hungria, firmados el } 16 / 12 / 91\end{array}$ & $25 / 02 / 93$ & $110 / 243$ \\
\hline C318 & $\begin{array}{l}\text { Tratado constitutivo de la Conferencia de Ministros } \\
\text { de Justicia de los países iberoamericanos, firmado } \\
\text { en Madrid el } 7 / 10 / 92\end{array}$ & $25 / 02 / 93$ & $110 / 245$ \\
\hline
\end{tabular}

Por su parte, de los cuarenta y cuatro tratados y convenios internacionales, de cuya existencia y contenido es necesario - según ya ha quedado expuesto - informar a las Cortes por imperativo del art. 94.2 CE, cabe resaltar que veinte de ellos tienen un carácter bilateral, versando lógicamente sobre asuntos muy puntuales que afectan a las relaciones entre España y sus respectivos países firmantes. Los veinticuatro restantes, que son los que hemos querido destacar por tener un carácter global o multilateral, pueden clasificarse, a efectos de facilitar su exposición detallada, en los siguientes cuatro grupos:

a) Los que desarrollan el Acuerdo de Ginebra de 20/03/1958, considerándose como sus Anejos:

- Reglamento n. ${ }^{\circ} 64$ sobre prescripciones uniformes relativas a la homologación de los vehículos provistos de ruedas y neumáticos de emergencia de uso temporal («B.O.C.G.» n.ํ C158; núm. de expediente: 111/043).

- Adhesión Reglamento n. $\stackrel{65}{6}$ sobre prescripciones uniformes relativas a la homologación de luces especiales de aviso para automóviles («B.O.C.G." n.ํ C164; núm. de expediente: 111/044). 


\begin{tabular}{|c|c|c|c|}
\hline "B.O.C.G." & Materia & Fecha debate & N. ${ }^{\circ}$ Expte. \\
\hline $\mathrm{C} 235$ & $\begin{array}{l}\text { Reglamento General de la Unión Postal de las } \\
\text { Américas, España y Portugal, hecho en Buenos Aires } \\
\text { el } 21 / 09 / 90\end{array}$ & $09 / 04 / 92$ & $110 / 176$ \\
\hline $\mathrm{C} 236$ & $\begin{array}{l}\text { Protocolo de privilegios e inmunidades de la } \\
\text { Organización Europea de Telecomunicaciones } \\
\text { por Satélite (EUTELSAT), hecho en Paris el 13/02/87 } \\
\text { y declaraciones a formular por España }\end{array}$ & $09 / 04 / 92^{\circ}$ & $110 / 177$ \\
\hline C246 & $\begin{array}{l}\text { Convenio sobre evaluación del impacto en medio } \\
\text { ambiente en un contexto transfronterizo, hecho en } \\
\text { Espoo (Finlandia) el } 25 / 2 / 91\end{array}$ & $28 / 05 / 92$ & $110 / 185$ \\
\hline $\mathrm{C} 255$ & $\begin{array}{l}\text { Acuerdo por el que se autoriza la adhesión de } \\
\text { España al Convenio Internacional sobre Búsqueda } \\
\text { y Salvamento Marítimo (Hamburgo, 27/04/1979) }\end{array}$ & $17 / 09 / 92$ & $110 / 190$ \\
\hline $\mathrm{C} 257$ & $\begin{array}{l}\text { Protocolo de } 1990 \text { que enmienda el Convenio de } \\
\text { Atenas (1974) relativo al transporte de pasajeros y } \\
\text { sus equipajes por mar (Londres, 29/03/90) }\end{array}$ & $17 / 09 / 92$ & $110 / 192$ \\
\hline $\mathrm{C} 258$ & $\begin{array}{l}\text { Convenio internacional sobre cooperación, } \\
\text { preparación y lucha contra la contaminación por } \\
\text { hidrocarburos, hecho en Londres el } 30 / 11 / 90\end{array}$ & $17 / 09 / 92$ & $110 / 193$ \\
\hline $\mathrm{C} 262$ & $\begin{array}{l}\text { Acuerdo retirada reserva española al Protocolo } \\
\text { relativo a la prohibición del empleo en la guerra } \\
\text { de gases asfixiantes, tóxicos o similares o de } \\
\text { medios bacteriológicos, hecho en Ginebra el } \\
17 / 06 / 1925\end{array}$ & $24 / 09 / 92$ & $110 / 197$ \\
\hline $\mathrm{C} 276$ & $\begin{array}{l}\text { Tratado de Cielos Abiertos, hecho en Helsinki el } \\
24 \text { de marzo de 1992, así como declaración a } \\
\text { formular por España }\end{array}$ & $29 / 10 / 92$ & $110 / 207$ \\
\hline C298 & $\begin{array}{l}\text { Convención marco de las Naciones Unidas sobre } \\
\text { cambio climático, hecha en Nueva York el 9/05/92 }\end{array}$ & $11 / 02 / 93$ & $110 / 227$ \\
\hline C299 & $\begin{array}{l}\text { Convenio sobre la diversidad biológica, hecho en } \\
\text { Río de Janeiro el 5/06/92 }\end{array}$ & $11 / 02 / 93$ & $110 / 228$ \\
\hline C307 & $\begin{array}{l}\text { Protocolo de enmienda al Convenio sobre } \\
\text { establecimiento de una Organización Europea } \\
\text { para la Explotación de Satélites Meteorológicos } \\
\text { (EUMETSAT) de } 24 / 05 / 1983 \text {, adoptado por } \\
\text { Resolución de su Consejo }\end{array}$ & $25 / 02 / 93$ & $110 / 237$ \\
\hline
\end{tabular}


- Reglamento $n$. 66 sobre prescripciones uniformes relativas a la homologación de vehículos de gran capacidad de transporte de personas, respecto a la resistencia mecánica de la superestructura («B.O.C.G.» n. ${ }^{\circ}$ C177; núm. de expediente: 111/048).

- Reglamento $n .078$ sobre prescripciones uniformes relativas a la homologación de los vehículos de la categoría $L$, en lo que concierne al frenado («B.O.C.G.» n.․․ C201; núm. de expediente: 111/062).

- Reglamento $n .948$ sobre prescripciones uniformes relativas a la homologación de vehículos, en lo concerniente a la instalación de dispositivos de iluminación y señalización luminosa ("B.O.C.G." n. C220; núm. de expediente: 111/067).

- Reglamento $n .-50$ relativo al cumplimiento de condiciones uniformes, homologación y reconocimiento recíproco de equipos y piezas de vehículos de motor (“B.O.C.G.” n. C239; núm. de expediente: $111 / 071)$.

- Serie 03 enmiendas al Reglamento n. 36 sobre prescripciones uniformes relativas a las características de construcción de vehículos de transporte público de personas («B.O.C.G.» n. ${ }^{\circ}$ C240; núm. de expediente: 111/072).

- Reglamento sobre prescripciones uniformes relativas a la homologación de dispositivos silenciadores para el escape de recambio de las motocicletas («B.O.C.G.» n. C241; núm. de expediente: 111/073).

- Reglamento n. 52 sobre prescripciones uniformes relativas a las características de construcción de vehículos de transporte colectivo de pequeña capacidad ("B.O.C.G." n. C332; núm. de expediente: 111/085).

- Reglamento revisado n. 16 sobre prescripciones uniformes relativas a la homologación de cinturones de seguridad y dispositivos de retención para los ocupantes adultos de vehículos automóviles («B.O.C.G.» n. ${ }^{\circ}$ C336; núm. de expediente: 111/088).

b) Los que aprueban diversos Acuerdos regionales:

- Planificación de la radiodifusión y televisión en la zona africana y países vecinos de la Unión Internacional de Telecomunicaciones («B.O.C.G.» n. C179; núm. de expediente: 111/049). 
- Servicios móvil marítimo y de radionavegación aeronáutica en la banda de ondas hectométricas en la Región I de la U.I.T. ("B.O.C.G." n.o C185; núm. de expediente: 111/052).

- Planificación servicios de radionavegación marítima (radiofaros) en la zona marítima europea de la U. I.T. ("B.O.C.G.» n. ${ }^{\circ}$ C186; núm. de expediente: $111 / 053)$.

c) Los que complementan Tratados o Convenios anteriores:

- Protocolo al Convenio n. 9134 del Consejo de Europa, relativo a la elaboración de una farmacopea europea («B.O.C.G." n. C199; núm. de expediente: 111/060).

- Cuarto Protocolo Adicional al Tratado constitutivo de la Unión Postal Universal («B.O.C.G.» n. C204; núm. de expediente: 111/064).

- Cuarto Protocolo Adicional a la constitución de la Unión Postal de las Américas, España y Portugal y resoluciones aprobadas en el XIV Congreso de la Unión Postal de las Américas, España y Portugal, el 21/09/90 («B.O.C.G.» n. C234; núm. de expediente: 111/070).

- Protocolo de 1988 relativo al Convenio Internacional sobre líneas de carga de 1966, hecho en Londres el 11/11/1988 («B.O.C.G." n.. C337; núm. de expediente: 111/090).

d) Los que modifican o derogan el contenido de Tratados o Convenios anteriores:

- Protocolo por el que se derogan las partes aún en vigor del Acuerdo Regional para la zona africana de radiodifusión (Ginebra, 1963), hecho en Ginebra el 5/12/89 ("B.O.C.G." n.o C165; núm. de expediente: 111/045).

- Revisión del Reglamento de Radiocomunicaciones de la Unión Internacional de Telecomunicaciones (Ginebra, 1988) y declaraciones $n$.. 62 y 81 formuladas por España («B.O.C.G.» n. C176; núm. de expediente: $111 / 047)$.

- III Enmienda al Convenio constitutivo del Fondo Monetario Internacional, adoptada el 28/06/1990 ("B.O.C.G." n.ำ C192; núm. de expediente: 111/058). 
- Modificación de la declaración que España proyecta formular al amparo del artículo 8 del Acuerdo sobre traslado de cadáveres, hecho en Estrasburgo el 26/10/73 («B.O.C.G.» n. C203; núm. de expediente: 111/063).

- Protocolo relativo a una enmienda al Convenio sobre Aviación Civil Internacional, hecho en Montreal el 26/10/90 («B.O.C.G." n. ${ }^{\circ}$ C266; núm. de expediente: 111/077).

- Resolución A.724(17) de la Asamblea General de la Organización Marítima Internacional, que incluye enmiendas al Convenio constitutivo de dicha Organización, aprobadas el 7/11/91 por su Asamblea General («B.O.C.G.» n.ํ C338; núm. de expediente: 111/091).

\section{DECRETOS-LEYES}

Durante el período analizado, se han convalidado doce DecretosLeyes, de los que cinco se han tramitado como leyes por el procedimiento de urgencia, conforme a lo dispuesto en el art. 86.3 CE. De todos ellos se da la siguiente relación detallada:

\begin{tabular}{llll}
\hline “B.0.E." & \multicolumn{1}{c}{ Denominación } & Convalid. & Trámite Ley \\
\hline 02/12/91 & $\begin{array}{l}\text { Real Decreto-Ley 4/1991, de 29 de noviembre, sobre } \\
\text { medidas urgentes para la progresiva adaptación del } \\
\text { sector petrolero al marco comunitario }\end{array}$ & $19 / 12 / 91$ & sí \\
\hline $21 / 12 / 91$ & $\begin{array}{l}\text { Real Decreto-Ley 5/1991, de 20 de diciembre, por el } \\
\text { que se dispone el comienzo de la aplicación del } \\
\text { Impuesto General Indirecto Canario el 1 de enero } \\
\text { de 1993 }\end{array}$ & $23 / 01 / 92$ & sí \\
\hline 07/04/92 & $\begin{array}{l}\text { Real Decreto-Ley 1/1992, de 3 de abril, de medidas } \\
\text { urgentes sobre fomento del empleo y protección } \\
\text { por desempleo }\end{array}$ & $30 / 04 / 92$ & sí \\
\hline $11 / 04 / 92$ & $\begin{array}{l}\text { Real Decreto-Ley 2/1992, de 10 de abril, sobre } \\
\text { concesión de varios suplementos de crédito por } \\
\text { un importe total de 21.670 millones de pesetas } \\
\text { para gastos de seguridad relacionados con la EXPO, } \\
\text { los Juegos Olimpicos y la capitalidad cultural } \\
\text { de Madrid }\end{array}$ & & \\
\hline
\end{tabular}




\begin{tabular}{|c|c|c|c|}
\hline "B.O.E." & Denominación & Convalid. & Trámite Ley \\
\hline $27 / 05 / 92$ & $\begin{array}{l}\text { Real Decreto-Ley } 3 / 1992 \text {, de } 22 \text { de mayo, por el } \\
\text { que se adoptan medidas urgentes para reparar } \\
\text { los efectos producidos por la sequía }\end{array}$ & $11 / 06 / 92$ & no \\
\hline $16 / 06 / 92$ & $\begin{array}{l}\text { Real Decreto-Ley } 4 / 1992, \text { de } 15 \text { de junio, sobre } \\
\text { concesión de un crédito extraordinario por importe } \\
\text { de } 195.781 .841 .611 \text { ptas., para atender las } \\
\text { insuficiencias producidas durante } 1990 \text { en el INEM } \\
\text { en materia de gestión de prestaciones por desempleo }\end{array}$ & $25 / 06 / 92$ & no \\
\hline $23 / 07 / 92$ & $\begin{array}{l}\text { Real Decreto-Ley } 5 / 1992 \text {, de } 21 \text { de julio, de } \\
\text { medidas presupuestarias urgentes }\end{array}$ & $28 / 07 / 92$ & sí \\
\hline $14 / 11 / 92$ & $\begin{array}{l}\text { Real Decreto-Ley } 6 / 1992 \text {, de } 13 \text { de noviembre, sobre } \\
\text { concesión de un crédito extraordinario de } 280.558 \\
\text { millones de pesetas para cancelar obligaciones } \\
\text { derivadas del coste de la asistencia sanitaria de la } \\
\text { Seguridad Social }\end{array}$ & $10 / 12 / 92$ & no \\
\hline $12 / 01 / 93$ & $\begin{array}{l}\text { Real Decreto-Ley } 1 / 1993 \text {, de } 8 \text { de enero, sobre } \\
\text { medidas urgentes en materia de gastos de personal } \\
\text { activo y concesión de un suplemento de crédito por } \\
\text { un importe de } 80.027 \text { millones de pesetas }\end{array}$ & $11 / 02 / 93$ & no \\
\hline $20 / 01 / 93$ & $\begin{array}{l}\text { Real Decreto-Ley } 2 / 1993 \text {, de } 15 \text { de enero, por el que } \\
\text { se adoptan medidas para paliar determinadas } \\
\text { consecuencias adversas del accidente del buque } \\
\text { "Aegean Sea" }\end{array}$ & $18 / 02 / 93$ & sí \\
\hline $02 / 03 / 93$ & $\begin{array}{l}\text { Real Decreto-Ley } 3 / 1993 \text {, de } 5 \text { de marzo, de medidas } \\
\text { urgentes sobre materias presupuestarias, tributarias, } \\
\text { financieras y de empleo }\end{array}$ & $11 / 03 / 93$ & no \\
\hline $30 / 03 / 93$ & $\begin{array}{l}\text { Real Decreto-Ley } 4 / 1993 \text {, de } 26 \text { de marzo, por el que } \\
\text { se autoriza el resarcimiento de los daños causados } \\
\text { como consecuencia de la rotura de la presa de Tous } \\
\text { y se concede un crédito extraordinario por importe } \\
\text { de } 19.000 \text { millones de pesetas }\end{array}$ & $27 / 04 / 93$ & no \\
\hline
\end{tabular}




\section{DECRETOS LEGISLATIVOS}

A lo largo del espacio temporal que venimos analizando, tan sólo una norma de este tipo ha sido tramitada en el Congreso de los Diputados. Se trata del Real Decreto Legislativo 1/1992, de 26 de junio, por el que se aprueba el Texto Refundido de la Ley sobre Régimen del Suelo y Ordenación Urbana. Su publicación tuvo lugar en el Boletín Oficial del Estado de fecha 30 de junio de 1992.

\section{PROPOSICIONES DE LEY}

Aunque para adoptar este tipo de iniciativa legislativa se hallan facultados, según el art. 126.1 RC, tanto los diputados de forma individual, como los grupos parlamentarios, en el período estudiado sólo estos últimos procedieron a hacerlo, resultando un número total de ochenta y tres proposiciones de ley. A tal número habría que añadir las diez presentadas por diversos Parlamentos autonómicos (que han pasado todas a la siguiente Legislatura) y otra más debida a la iniciativa popular, que versaba sobre la promoción y regulación del ejercicio, disfrute y comercialización del arte, y que no fue admitida a trámite. Hubo, además, una proposición de ley para la reforma del Reglamento del Congreso que, conforme a lo dispuesto en la Disposición Final 2. ${ }^{\text {a }}$ de dicho texto legal, fue presentada a iniciativa del propio Congreso y que resultó tomada en consideración por mayoría absoluta. Así pues, el cuadro estadístico que resulta de la iniciativa de los grupos parlamentarios en este apartado es el siguiente:

\begin{tabular}{|c|c|c|c|c|c|c|c|c|}
\hline \multirow{2}{*}{$\begin{array}{l}\text { Proposiciones } \\
\text { de ley }\end{array}$} & \multicolumn{8}{|c|}{ Grupos } \\
\hline & $C t$ & $\cos$ & $U$ & $M x$ & $P p$ & Sc & $V c$ & Varios \\
\hline Presentadas.......... & 10 & 8 & 16 & 2 & 37 & 1 & 5 & 4 \\
\hline $\begin{array}{l}\text { Tomadas en } \\
\text { consideración.... }\end{array}$ & 1 & - & 3 & 一 & 1 & 1 & - & 2 \\
\hline Rechazadas............ & 3 & 4 & 10 & - & 21 & - & 2 & 1 \\
\hline Caducadas ............... & 3 & 3 & 3 & 1 & 13 & 一 & 2 & 1 \\
\hline Retiradas.................... & 3 & 1 & - & 1 & 2 & 一 & - & - \\
\hline No admitidas ........ & - & - & - & - & - & 一 & 1 & - \\
\hline
\end{tabular}


En definitiva, y según se observa en el cuadro adjunto, fueron ocho las proposiciones de ley tomadas en consideración, que son las que a continuación se relacionan:

a) Del Grupo Catalán:

- Modificación del art. 70.2 de la Ley $7 / 1985$, de 2 de abril, reguladora de las Bases del Régimen Local («B.O.C.G.» n.․149; fecha de aprobación: 23/02/93).

b) Del Grupo Izquierda Unida:

- Modificación del art. 73 de la Ley Orgánica del Régimen Electoral General («B.O.C.G.» n. 107; fecha de aprobación: 3/03/92).

- Modificación del Estatuto de los Trabajadores en materia de indemnizaciones en los supuestos de extinción contractual por jubilación del empresario ("B.O.C.G.» n. 115; fecha de aprobación: 26/05/92).

- Modificación de la Ley 26/1990, de 20 de diciembre, sobre revalorización periódica de la asignación económica por hijo a cargo ("B.O.C.G." n. 116; fecha de aprobación: 9/06/92).

c) Del Grupo Popular:

- Modificación de la legislación vigente en materia de incompatibilidades e intereses de los altos cargos y de los miembros de las Corporaciones Locales («B.O.C.G.» n.ำ 135; fecha de aprobación: 16/02/93).

d) Del Grupo Socialista:

- Modificación de la Ley sobre regulación de las atribuciones profesio-

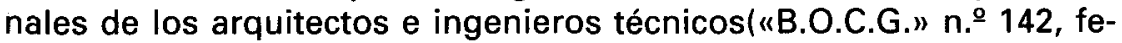
cha de aprobación: 22/09/92). 
e) Conjunta de los Grupos Catalán, Centro Democrático y Social, Socialista y Vasco:

- Reforma de la Ley Orgánica de Régimen Electoral General, sobre reducción de gastos electorales ("B.O.C.G." n. 0 162; fecha de aprobación: 9/02/93).

f) Conjunta de todos los Grupos, excepto el Popular:

- Modificación de la Ley de Bases de delegación al Gobierno para la aplicación del Derecho Comunitario ("B.O.C.G." n.ำ 165; fecha de aprobación: 9/02/93). 